Case Report

\title{
Sarcomatoid Variant of Urothelial Carcinoma of the Renal Pelvis with Inferior Vena Cava Tumour Thrombus: A Case Report and Literature Review
}

\author{
Sameera Rashid $(D)$ and Mohammed Akhtar \\ Department of Laboratory Medicine and Pathology, Hamad Medical Corporation, Doha, Qatar \\ Correspondence should be addressed to Sameera Rashid; srashid2@hamad.qa
}

Received 19 September 2017; Accepted 20 December 2017; Published 17 January 2018

Academic Editor: Maria M. Picken

Copyright (C) 2018 Sameera Rashid and Mohammed Akhtar. This is an open access article distributed under the Creative Commons Attribution License, which permits unrestricted use, distribution, and reproduction in any medium, provided the original work is properly cited.

\begin{abstract}
Sarcomatoid variant of urothelial carcinoma (SVUC) of the renal pelvis is a rare entity. To the best of our knowledge, around 25 cases of this neoplasm have been reported in the literature to date, most of which were of high stage. The inferior vena cava tumour thrombus, which is a hallmark of renal cell carcinoma (RCC), may rarely be found in urothelial carcinoma of renal pelvis. In this report, a case of SVUC associated with tumour extension to inferior vena cava is documented. This association has been encountered in only one previously reported case. The possibility of urothelial carcinoma of the renal pelvis should therefore be included in the differential diagnosis of tumour thrombus of the inferior vena cava.
\end{abstract}

\section{Introduction}

Carcinoma of the kidney and renal pelvis represents the eighth most common cancer in the United States with an estimated 63,990 new cases and 14,400 deaths by renal tumours in the year 2017 [1]. Urothelial carcinoma (UC) accounts for 10 to $15 \%$ of all primary renal malignancies, with the most common malignant tumour being renal cell carcinoma (RCC). Inferior vena cava tumour thrombus, which is a hallmark of RCC, is rarely found in urothelial carcinoma. Similar vena cava tumour thrombi, however, are found in less common retroperitoneal primary neoplasms such as Wilms' tumour and various adrenal, uterine, and urinary bladder tumours [2].

Sarcomatoid variant of urothelial carcinoma (SVUC) of the renal pelvis is a rare tumour with aggressive clinical behaviour [3]. Around twenty-five cases of SVUC arising from the renal pelvis have been reported [4-12]. Of these only one presented with tumour thrombus in the inferior vena cava. We report one more case of SVUC with involvement of the inferior vena cava.

\section{Case Report}

A 70-year-old male presented with urgency, urinary incontinence, and nocturia for five days. The patient was known to have benign prostatic hyperplasia (on Tamsulosin) and had a long- standing history of anaemia. No palpable abdominal mass was detected during the physical examination. His laboratory evaluation revealed anaemia (haemoglobin: $8.5 \mathrm{mg} / \mathrm{dl}, \mathrm{MCV}: 80 \mathrm{fl}, \mathrm{MCH} 24.8 \mathrm{pg}, \mathrm{MCHC} 30.9 \mathrm{gm} / \mathrm{dl}$, WBC $14 \times 10^{3} /$ microliter, creatinine 90 micromole/dl, and platelet $156 \mathrm{ng} / \mathrm{ml})$.

Ultrasound of the renal system showed a right renal mass. An abdominal computed tomography (CT) revealed an illdefined infiltrative $4 \mathrm{~cm}$ renal mass in the mid to lower pole region of the right kidney, involving the renal parenchyma, renal hilum, and the renal pelvis (Figure 1). Similar findings were also noted on a magnetic resonance imaging (MRI) which also revealed a tumour thrombus extending along the entire course of the right renal vein and projecting into the right side of the lumen of the inferior vena cava (Figure 2).

A right laparoscopic radical nephroureterectomy with thrombectomy of the inferior vena cava was performed. The 


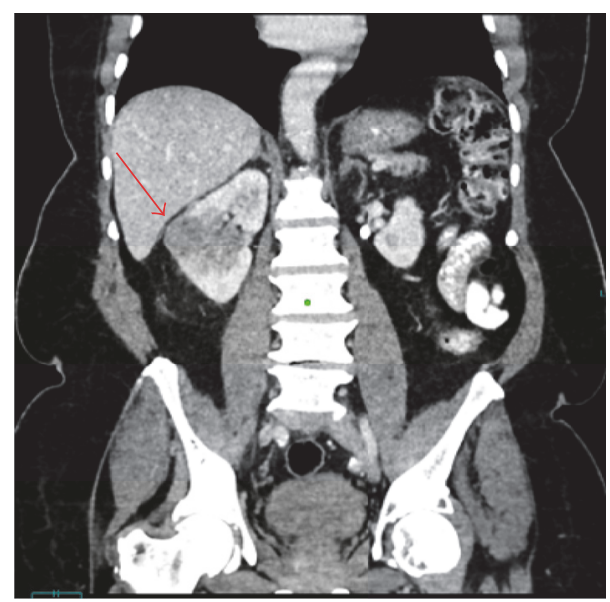

FIGURE 1: Computed tomography with contrast (CT) coronal image demonstrates a heterogeneously enhancing hypodense right renal mid pole mass (red arrow) occupying the renal cortex and renal pelvis with mild surrounding fat stranding.

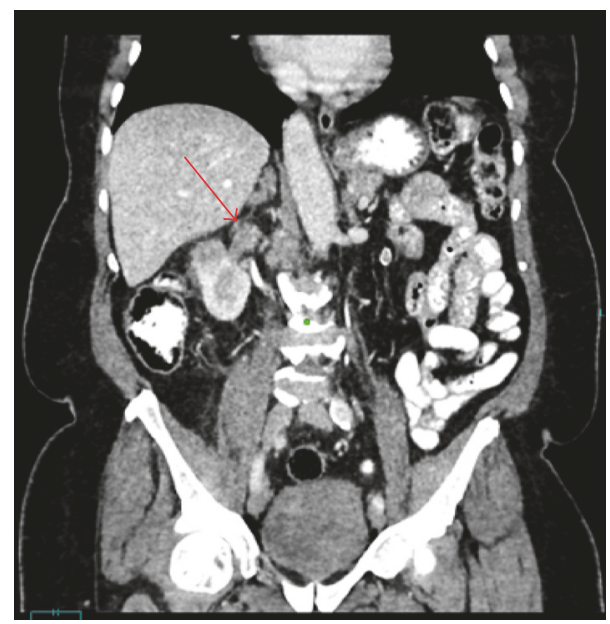

FIGURE 2: Contrast enhanced computed tomography coronal image demonstrates tumoural thrombus within the right renal vein (red arrow).

right kidney was enlarged, solid, and adherent to perirenal adipose tissue. The middle and lower part of right ureter were dilated. The thrombus was gently milked from the inferior vena cava and removed separately.

Gross examination of the nephrectomy specimen showed a $5.5 \times 4.5 \times 4.5 \mathrm{~cm}$ greyish tan friable mass arising in the renal pelvis, projecting into the proximal ureter, and extensively infiltrating the adjacent renal parenchyma (Figure 3).

Histological examination revealed a high grade urothelial carcinoma with sarcomatoid differentiation. The tumour was arising in the renal pelvis with infiltration of the renal parenchyma and extension into renal sinus and the renal vein. Carcinoma in situ involving the adjacent urothelium was noted (Figure 4).

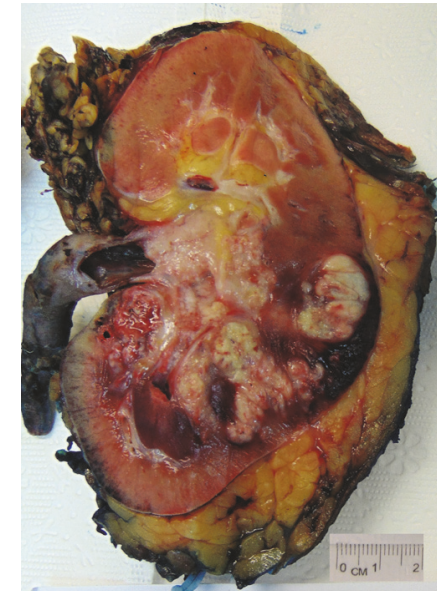

FIGURE 3: Right kidney with attached ureter showing tumour arising from the renal pelvis projecting into the proximal ureter and infiltrating the renal parenchyma.

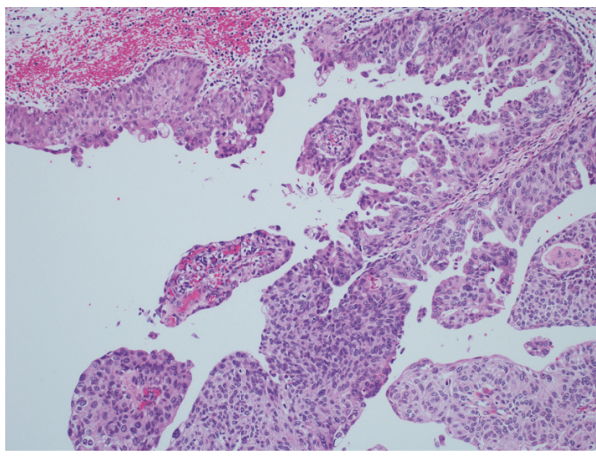

FIGURE 4: A low power view of the papillary urothelial carcinoma projecting into the renal pelvis. Carcinoma in situ is present in the adjacent urothelial mucosa.

The sarcomatoid elements were composed of spindle shaped cells with marked nuclear pleomorphism and high mitotic activity (Figures 5 and 6).

Extensive areas of tumour necrosis were also seen. The resection margin of the ureter was free of tumour. The tumour thrombus from the inferior vena cava was composed of high grade urothelial carcinoma along with the sarcomatoid component (Figure 7).

On immunohistochemistry the carcinoma component was positive for CK7, CK20, p63, p53, and GATA-3, while the sarcomatous component stained strongly and diffusely positive for vimentin. Both components did not show any staining for desmin or smooth muscle actin (Table 1).

\section{Discussion}

Renal cell carcinoma (RCC) is known to have a predisposition for vascular invasion, and in $10-25 \%$ cases tumour thrombus may extend into the inferior vena cava [13]. However, urothelial carcinoma arising from the renal pelvis rarely invades IVC. Although 25 cases of IVC involvement by urothelial 
TABLE 1: Comparison of immunohistochemistry findings in the sarcomatous and urothelial components.

\begin{tabular}{lcc}
\hline Antibody & Carcinoma component & Sarcomatoid component \\
\hline CK 7 & Diffusely positive, strong intensity & Weak, focal positive \\
CK 20 & Focally positive, strong intensity & Negative \\
p53 & Focally positive, strong intensity & Negative \\
P63 & Diffusely positive, strong intensity & Negative \\
GATA-3 & Diffusely positive, strong intensity & Weak, focal positive \\
Vimentin & Negative & Diffusely positive, strong intensity \\
Desmin & Negative & Negative \\
Smooth muscle action & Negative & Negative \\
\hline
\end{tabular}

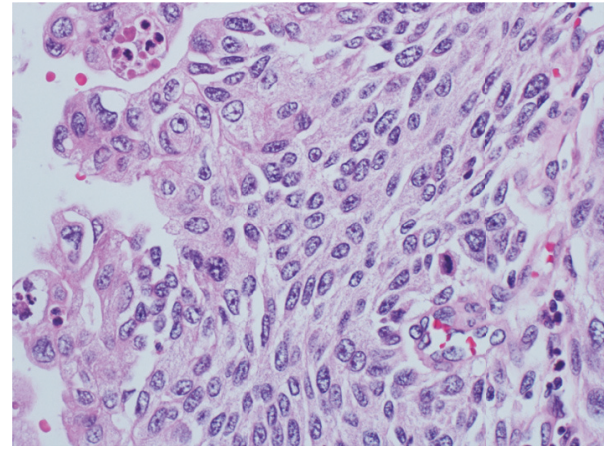

FIGURE 5: Photomicrograph depicting high grade urothelial carcinoma with transformation to sarcomatoid carcinoma characterized by a spindle cell pattern.

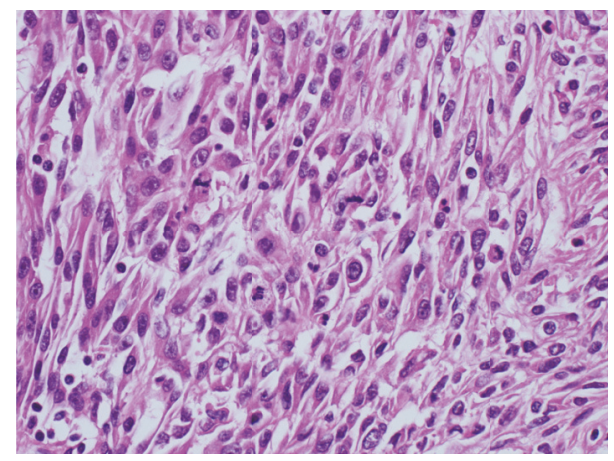

Figure 6: Higher magnification photomicrograph featuring sarcomatoid component with spindle proliferation, nuclear pleomorphism, and increased mitotic activity.

carcinoma are reported in the English literature, there has been only one previously reported case of SVUC extension into IVC [14].

Sarcomatoid variant of urothelial carcinoma is an aggressive but uncommon type of urothelial carcinoma with around 100 reported cases, an overwhelming majority of which arise in the urinary bladder [15-17]. In the literature, these tumours have also been designated as carcinosarcoma and spindle cell carcinoma [17]. Lopez-Beltran et al. [6] stated that microscopically sarcomatoid urothelial carcinoma contains a urothelial, glandular, or small cell component with variable degrees of differentiation and that carcinoma in situ is

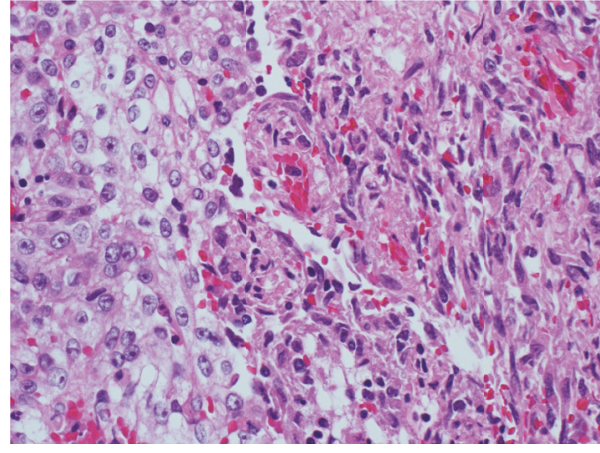

FIgURE 7: Tumour thrombus from the inferior vena cava with high grade urothelial carcinoma and the sarcomatoid component.

found in $30 \%$ of these cases. Occasionally carcinoma in situ is the only identifiable epithelial component in these cases. Heterologous mesenchymal sarcomatoid elements may occasionally be encountered in SVUC, with most common component being osteosarcoma followed by chondrosarcoma components.

Two opposing theories have been proposed regarding the pathogenesis of SVUC. The monoclonal theory states that the carcinomatous and sarcomatous tumour cells are both derived from a single pluripotent stem cell. The multiclonal theory, on the other hand, states that the sarcomatoid carcinoma is a collision tumour composed of the derivatives of two or more stem cells of separate epithelial and mesenchymal origin $[18,19]$. Eble et al. stated that sarcomatoid variant of urothelial carcinoma is the most appropriate terminology that should be used for all biphasic malignant neoplasms which exhibit morphologic and/or immunohistochemical evidence of epithelial and mesenchymal differentiation with or without heterologous elements [4]. The WHO classification system acknowledges the controversy surrounding this issue but refers to these lesions as sarcomatoid variant of urothelial carcinoma [4].

Sarcomatoid variant of urothelial carcinoma of the renal pelvis is a rare entity with approximately 25 reported cases. A poor prognosis has been reported for most patients, and only a few patients have survived for more than two years after diagnosis [4-12]. To the best of our knowledge, inferior vena cava tumour thrombus in a patient with SVUC of renal pelvis has been documented only once before in a case reported 
by Wick and Swanson [20]. This was a 61-year-old man who presented with a right renal mass with a vena caval thrombus, demonstrated on computed tomography, that was radiologically diagnosed as renal cell carcinoma. The results of routine laboratory examinations and urinalysis were within normal limits. Preoperative planning was critical owing to the presence of the vena caval thrombus. A radical nephrectomy, vena caval thrombectomy, and regional lymphadenectomy were done. The pathologic report was consistent with a high grade, invasive urothelial carcinoma, with sarcomatoid differentiation arising in the renal pelvis and involving the renal vein and inferior vena cava. Our report is the second case of SVUC of the renal pelvis with inferior vena cava tumour thrombus. Since vena caval involvement is usually associated with renal cell carcinoma, this finding in the CT scan may lead to an erroneous impression of renal cell carcinoma.

The differential diagnosis of SVUC includes primary renal sarcoma and renal cell carcinoma with sarcomatoid differentiation. Both lesions are rare. Adult renal sarcoma accounts for $0.8 \%$ of renal cancer cases and generally has a poor prognosis [21]. RCC with sarcomatoid features is also associated with a poor prognosis, but unlike renal carcinoma targeted therapy has no clear benefits [22]. Treatment of inferior vena cava tumour thrombus should be based on the primary pathology and natural behaviour of a given tumour in a specific patient rather than only focusing on the level and extent of venous invasion [21].

\section{Conclusion}

A rare case of SVUC arising in the renal pelvis with inferior vena cava tumour thrombus is documented. As inferior vena cava tumour thrombus is more common with renal cell carcinoma, these cases are usually diagnosed preoperatively as renal cell carcinoma. However, as this case demonstrates, renal vein and inferior vena cava involvement may also be seen in urothelial carcinomas arising in the renal pelvis.

\section{Conflicts of Interest}

The authors declare that they have no conflicts of interest.

\section{References}

[1] N. Howlader, A. M. Noone, M. Krapcho et al., Eds., SEER Cancer Statistics Review, 1975-2014, National Cancer Institute, Bethesda, MD, USA, 2017, based on November 2016 SEER data submission, posted to the SEER web site https://seer.cancer.gov/ csr/1975_2014/.

[2] D. Didier, A. Racle, J. P. Etievent, and F. Weill, “Tumor thrombus of the inferior vena cava secondary to malignant abdominal neoplasms: US and CT evaluation," Radiology, vol. 162, no. 1, pp. 83-89, 1987.

[3] J. K. Kim, K. C. Moon, C. W. Jeong, C. Kwak, H. H. Kim, and J. H. Ku, "Variant histology as a significant predictor of survival after radical nephroureterectomy in patients with upper urinary tract urothelial carcinoma," Urologic Oncology: Seminars and Original Investigations, vol. 35, no. 7, pp. 458-458.e15, 2017.
[4] J. N. Eble, G. Sauter, J. I. Epstein, and I. A. Sesterhenn, Pathology and Genetics of Tumours of the Urinary System and Male Genital Organs, vol. 1 of World Health Organization Classication of Tumours, IARCPress, Lyon, France, 2004.

[5] S. Suster and M. J. Robinson, "Spindle cell carcinoma of the renal pelvis. Immunohistochemical and ultrastructural study of a case demonstrating coexpression of keratin and vimentin intermediate filaments," Archives of Pathology \& Laboratory Medicine, vol. 113, no. 4, pp. 404-408, 1989.

[6] A. Lopez-Beltran, A. L. Escudero, A. O. Cavazzana, L. G. Spagnoli, and L. Vicioso-Recio, "Sarcomatoid transitional cell carcinoma of the renal pelvis: a report of five cases with clinical, pathological, immunohistochemical and DNA ploidy analysis," Pathology-Research and Practice, vol. 192, no. 12, pp. 1218-1224, 1996.

[7] T. Hisataki, A. Takahashi, K. Taguchi et al., "Sarcomatoid transitional cell carcinoma originating from a duplicated renal pelvis," International Journal of Urology, vol. 8, no. 12, pp. 704706, 2001.

[8] D. D. Thiel, T. C. Igel, and K. J. Wu, "Sarcomatoid carcinoma of transitional cell origin confined to renal pelvis," Urology, vol. 67, no. 3, pp. 622-e11, 2006.

[9] G. M. Chen, S. W. Chen, D. Xia, J. Li, S. Yan, and B. Y. Jin, "Sarcomatoid carcinoma of the renal pelvis in duplex kidney," Chinese Medical Journal (English), vol. 124, pp. 2074-2076, 2011.

[10] N. Arita, M. Ishida, K. Yoshida et al., "Sarcomatoid variant of urothelial carcinoma: cytological analysis of three cases," Oncology Letters, vol. 5, no. 1, pp. 49-52, 2012.

[11] A. M. Canacci and G. T. MacLennan, "Sarcomatoid urothelial carcinoma of the renal pelvis," The Journal of Urology, vol. 175, no. 5, p. 1906, 2006.

[12] X. Tian, J. Zhao, Y. Wang, and N. Xing, "Sarcomatoid carcinoma of the renal pelvis: a case report," Oncology Letters, vol. 8, no. 3, pp. 1208-1210, 2014.

[13] S. P. Psutka and B. C. Leibovich, "Management of inferior vena cava tumor thrombus in locally advanced renal cell carcinoma," Therapeutic Advances in Urology, vol. 7, no. 4, pp. 216-229, 2015.

[14] M. Li, A. Shi, W. Kong et al., "Transitional cell carcinoma with extension of the renal vein and IVC tumor thrombus: report of three cases and literature review," World Journal of Surgical Oncology, vol. 14, no. 1, article no. 309, 2016.

[15] Q. Zhai, J. Black, and A. Ayala, "Histologic Variants of Infiltrating Urothelial Carcinoma," Archives of Pathology and laboratory Medicine, vol. 131, no. 8, pp. 1244-56, Aug 2007.

[16] D. Perez-Montiel, P. E. Wakely Jr., O. Hes, M. Michal, and S. Suster, "High-grade urothelial carcinoma of the renal pelvis: clinicopathologic study of 108 cases with emphasis on unusual morphologic variants," Modern Pathology, vol. 19, no. 4, pp. 494-503, 2006.

[17] A. K. Venyo and S. Titi, "Sarcomatoid Variant of Urothelial Carcinoma (Carcinosarcoma, Spindle Cell Carcinoma): a Review of the Literature," ISRN Urology, vol. 2014, pp. 1-9, 2014.

[18] R. R. Diaz, J. K. Kwon, J. Y. Lee et al., "Renal pelvic urothelial carcinoma with vena caval thrombus mimicking renal cell carcinoma," Korean Journal of Urology, vol. 55, no. 9, pp. 624627,2014

[19] C. A. BLOXHAM, M. K. BENNETT, and M. C. ROBINSON, "Bladder carcinosarcomas: three cases with diverse histogenesis," Histopathology, vol. 16, no. 1, pp. 63-67, 1990.

[20] M. R. Wick and P. E. Swanson, "Carcinosarcomas: current perspectives and an historical review of nosological concepts," Seminars in Diagnostic Pathology, vol. 10, no. 2, pp. 118-127, 1993. 
[21] X. Wang, R. Xu, L. Yan et al., "Adult renal sarcoma: Clinical features and survival in a series of patients treated at a highvolume institution," Urology, vol. 77, no. 4, pp. 836-841, 2011.

[22] S. K. Keskin, P. Msaouel, K. R. Hess et al., "Outcomes of patients with renal cell carcinoma and sarcomatoid dedifferentiation treated with nephrectomy and systemic therapies: comparison between the cytokine and targeted therapy eras," The Journal of Urology, vol. 198, no. 3, pp. 530-537, 2017. 


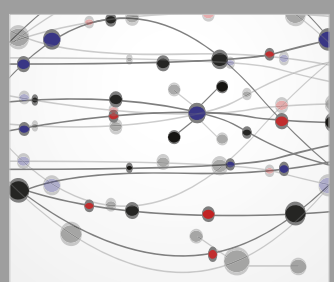

The Scientific World Journal
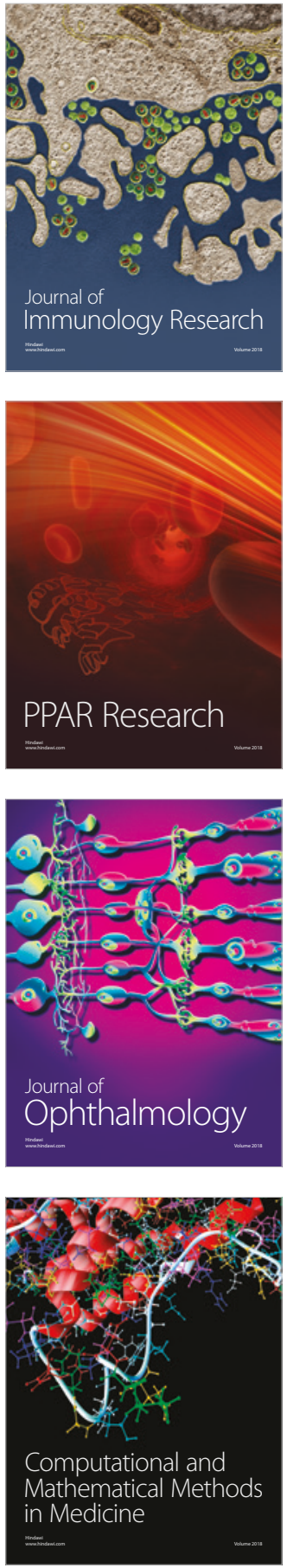

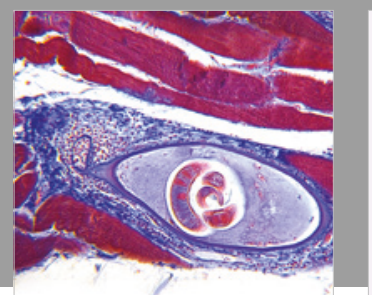

Gastroenterology Research and Practice

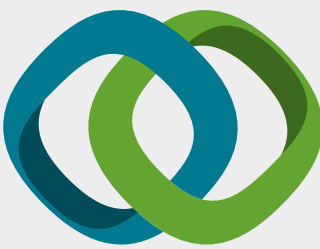

\section{Hindawi}

Submit your manuscripts at

www.hindawi.com
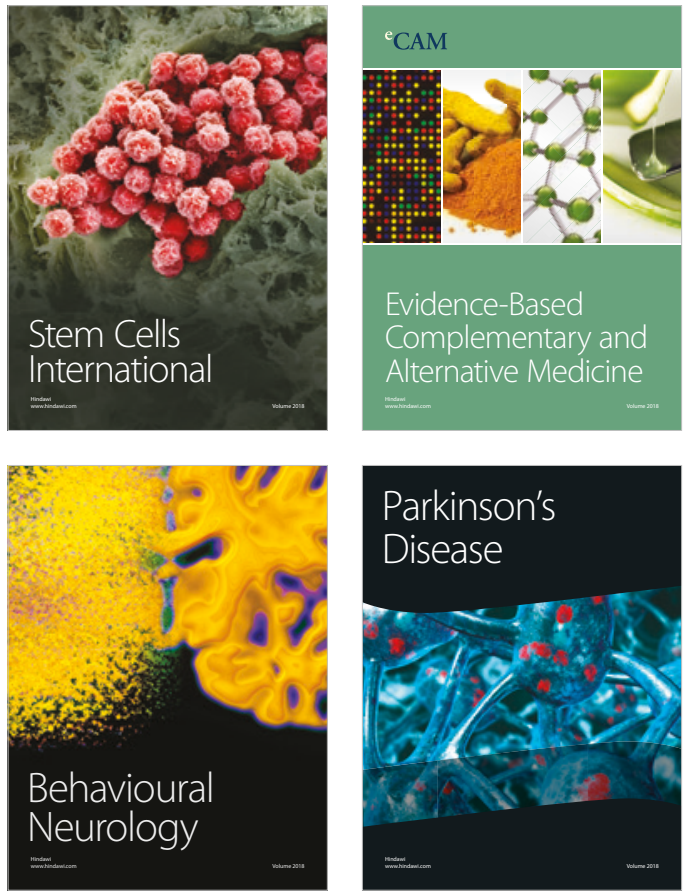

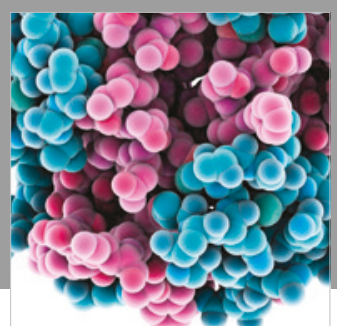

ournal of

Diabetes Research

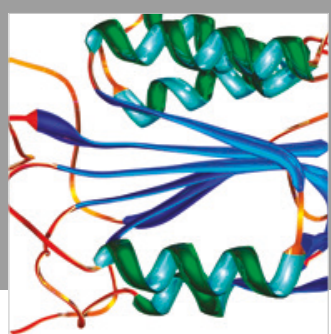

Disease Markers
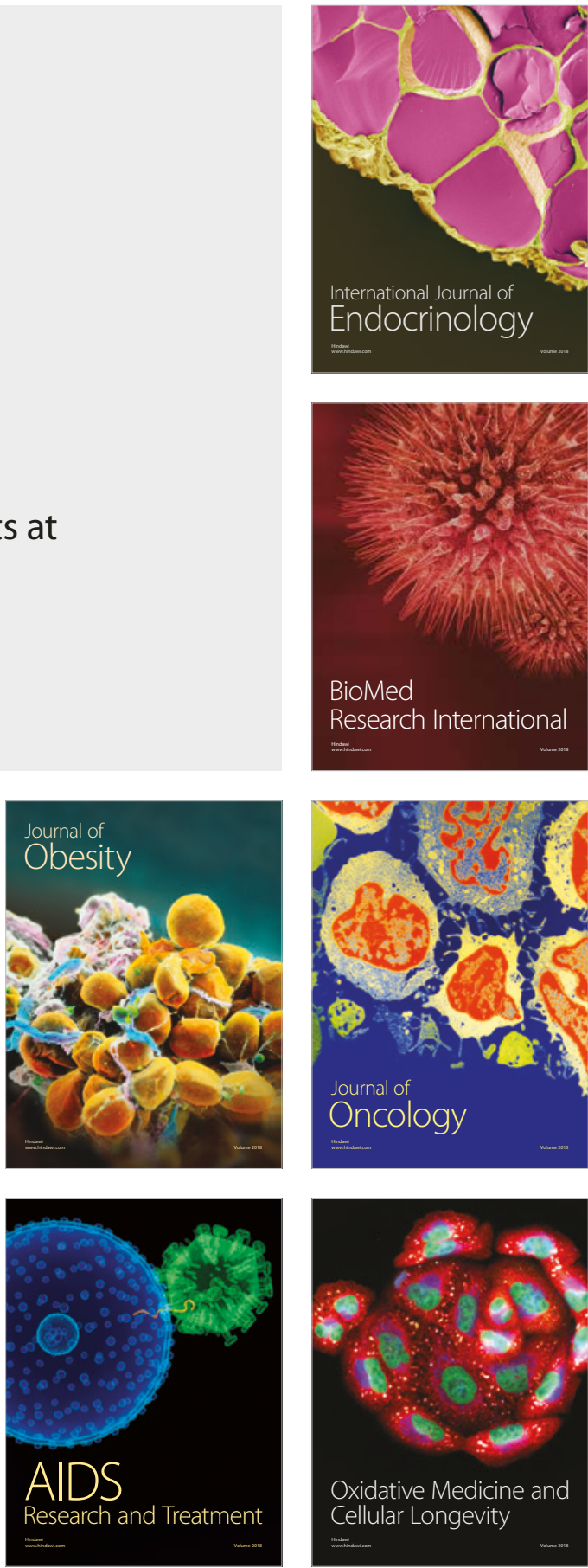